\title{
Native and Modified Starches as Matrix for Edible Films and Covers
}

\author{
Elevina E Pérez $S^{* 1}$ and Dominique Dufour ${ }^{2}$ \\ ${ }^{1}$ Instituto de Ciencia y Tecnología de Alimentos, Facultad de Ciencias, Universidad Central de Venezuela. \\ ${ }^{2}$ Centre de coopération internationale en recherche agronomique pour le développement (CIRAD), UMR Qualisud, France
}

Submission: August 30, 2017; Published: October 13, 2017

*Corresponding author: Elevina E. Pérez S. Instituto de Ciencia y Tecnología de Alimentos, Facultad de Ciencias, Universidad Central deVenezuela, Venezuela; Email: perezee@hotmail.com

\begin{abstract}
Among the natural n-polymers for to elaborate edible films is the starch. Though, it by itself can not to develop satisfactorily the properties to produce an adequate film. Native starches have several drawbacks associated to their hydrophilic properties that limit its function as barrier The plasticizers, improves the characteristics and properties of the films, in addition it has been used native starch reinforced with non-starchy components, as palliative. However, a best solution could be the use of modified starch, which help them to reach those barrier properties that making them applicable to the function desired. Films from cross linked starch tend to be permeable to water vapor and have higher hydrophilic properties, which increased its thickness, permeability, solubility, and stability in acidic and alkaline medium. Acetylated starch-based films shown stability to the decomposition by temperature, but are sensible to degradation. Starch dual modified have produced films with strong tensile strength, elongation at break and solubility, while the transparency value decrease. The sequence in the procedure of the modification duality has impact on the structure of the films. The chapter complicate and discusses the aspect regards to the use of modified starch as matrix for to produce films and coating.
\end{abstract}

Keywords: Starch; Films and cover; Plasticizers; Modified Starch; Functional Properties

\section{Introduction}

Edible film and coating are defined as a thin layer elaborated from components generally recognized as safe substances (GRAS) such as; proteins, polysaccharides and/or lipids, which can be consumed, coat food or placed as barrier between the food and the surrounding environment. Films and coatings can be elaborated from proteins, polysaccharides and/or lipids. There exist differences between the terms films and coating; films are elaborated as an individual item, and are free standing, whereas, coatings are formed directly on the food product, covering and isolating them from the environment. Edible films and coatings can help meet the many challenges involved with the marketing of foods, due they make them safe, nutritious, safe, of high quality, stable, and economical $[1,2]$. The most important functionalities of an edible film or coating include control of mass transfers, mechanical protection, and sensory appeal. Its functions can be pictured as: -carrier of ingredients that can proportion a special property to the food, or -by itself functional properties; such as mechanical resistance, solubility, transparency.

Most food consumed comes directly from nature, where many of them can be eaten immediately as we take them from the tree, or ground. However, with increased transportation distribution systems, storage needs, and advent of ever larger supermarkets and warehouse stores, foods are not consumed just in the orchard, on the field, in the farmhouse, or close to processing facilities. It takes considerable time for a food product to reach the table of the consumer. During time-consuming steps involved in handling, storage and transportation, products start to dehydrate, deteriorate, and lose appearance, flavor and nutritional value. If not special protection is provided, damage can occur within hours or days, even if this damage is not immediately visible [2]. The special protection can come from a coating that must be edible and it can also improve the functional, nutritional and appearance of the carrier food. Therefore, numerous researches has been done in its context, that will be discuss in this chapter. Moreover, films and coating as bioplastic matters are considered as promising biodegradable items in packing development. Alongside simple, foamed packaging chips (loose fill) based on starch, which can also be colored and used as children's toys, there is now a huge number of packaging items made from bio-plastics. Technically almost everything can be done: bio-plastics can be blown as film or multilayer film, or 
extruded as flat film. They can be thermoformed and are able to be printed, glued and converted into packaging components in numerous ways. In short: packaging manufacturers and packers can process bio-plastics on almost all of their usual machines with no problems [1]. Established packaging applications for bio-plastics are shopping bags, which also have a secondary use as a bag to collect compostable kitchen and garden waste. Further applications are thermoformed inserts for chocolate boxes, trays for fruit, vegetables, meat and eggs (also foamed), tubs for dairy produce, margarine and sandwich -spread, bottles, nets or pouches for fruit and vegetables. Blister packs, where the film is closely formed to follow the profile of the packaged product, can also be produced. Starches based packaging flakes made from bioplastics with barrier properties, impenetrable to odors and with good performance on the machines are available now, and are also the subject of continuous ongoing development [3]. Coating of paper and cardboard laminates with bio-plastics leads to new packaging with good moisture and fat or oil resistance [4]. In the USA, a mineral water bottle made from PLA bio-plastic had been launched in 2005. This was followed by a range of other bottles for water, milk and juice in North America, Europe, Australia, New Zealand and other regions. Disposal of used packaging made from bio-plastic can be carried out in various ways. As a rule, catering products are short-lived, like packaging. Once they have been used cups, plates and cutlery are thrown into the rubbish bin with any waste food clinging to them, and during festivals and other large-scale events soon build up into considerable amounts. Here bio-based plastics offer not only real ecological alternatives. They are also compostable and so can be disposed of together with the food remnants [3].

As was early mentioned, films and coating can be elaborated from native starch. However, even with its natural forming film properties, the native starch show limitations, in some of the functional properties, expected as films or coatings. The functional, organoleptic, nutritional, and mechanical properties of an edible film, can be modified by the addition of various chemicals in minor amounts; the plasticizers. However, even with the addition of plasticizer some properties cannot be obtained, and the use of mixtures of starch with other nonamylaceous film forming components has been experienced. In order to achieve an optimization in the properties of the films, it has been proposed the use of modified starches. Modification of starch is carried out to enhance the positive attributes and eliminate the shortcomings of the native starches. So, the processors of the starch industry have explored some properties of modified starches that can be useful to perform films and covers with optimal quality to provide those specific functional properties. Modification of starch is an everevolving industry with numerous possibilities to generate novel starches which includes new functional and value-added properties as a result of modification and as demanded by the manufacturing. The modification of native starch properties addressing them to a specific use can be brought about by using chemical, physical, or biological techniques, which may improve or introduce the desire functionality in their structure. The chapter will compilate and discuss some of the numerous researches of the use of native starch, waxy starch, native starch reinforced with other materials, and modified starch, as ingredient to perform edible films and covers, elucidating those properties of barrier that make them applicable to the function desired.

\section{Native starch as film forming substrate}

Eco efficient products are the new generation of bio based products prepared with sustainable materials, that agree with ecological and economic requirements including environmentally acceptable disposal of post-user waste [5]. As have been previously pointed out among the natural promising polymers there is the starch. Starch is a carbohydrate mainly composed of amylose and amylopectin, which is present in the granules in a proportion, which is function of the botanical source. Amylose structure has been considered as a linear chain of D-glucose units linked together by $\alpha-1,4$ bonds [6]. But in most starches one-third to two thirds of the amylose fraction has secondary chains attached through occasional $\alpha-1,6$ branch point, and in some species, has a few phosphate groups, probably at C- 6 of glucose residue. The brand chains are usually moderately long, but few may be as small as glucosyl to maltotetraosyl (G1-G4) [7]. It length or degree of polarization, which is varying from 102 to 104 glucose units have presence of cross linked bonds and phosphorus linked, which are also dependent of the botanical sources. Amylopectin consist of short chains, on average, 20 to $30 \alpha-1,4$ bonds linked D-glucose units, which are cross-linked by $\alpha-1,6$ bonds. It may consist of 104 to 105 glucose units [6]. The chain lengths and chain length distribution of amylopectin have showed differences among starch type from same species, with a decreased degree of multiples branching accompanying increased starchlipid and amylose content [8]. During the synthesis amylose and amylopectin are deposited in starch granules together with small amount of lipids, proteins and phosphorous (as phospholipids), which also vary with the botanical source, and must be drawn during isolation and purification of the starch; otherwise they could affect its purity. Therefore, industrial manufacture of starch involves freeing of starch granules from constituents such as; fiber, protein and extraneous materials, purifying by screening, washing, dewatering and drying.

Lipids in the starch granules are present on the surface and internally. It is proposed [9] that lipids on the surface of starch granules should be called "starch surface lipids", and that those inside the granules should be called "internal starch lipids". Starch surface lipids appear to be derived from the "non-starch lipids" which are either free or bound to proteins in the starch-bearing tissues. In cereals, the internal starch lipids are exclusively monoacyl lipids, and they are 
quite different in composition from the starch surface lipids and non-starch lipids. Inside the starch granules, internal starch lipids are complexed with the amylose and also with some branch of the amylopectin [10], and some functional properties are mainly determined by the lipid and amylose content of the starch granules and the degree that the amylose is polymerized. Indeed, the lipid component in the coating formulation can serve as a good barrier to water vapor, and it could be of interest for the mechanism plasticizing. The complex lipid-amylose or lipid-amylopectin branch and the amount of amylose could be also be related to the plasticizing. Lipid presence decreased significantly $(p<0.05)$ water vapor permeability of starch based films due to its hydrophobicity, as was pointed out by García et al. [1]. Same authors also have postulated that amylose molecules without plasticizer produce crystalline and brittle films.

Sources of starch commonly used in food technology and commercial applications of the food industry are limited [11]. The starch utilized world-wide come from a relatively few crops, the most important being maize, potato wheat and tapioca, with smaller amount from rice, sorghum, sweet potato, arrowroot sago and mung bean [8].The technologies of starch isolation, purification and modification have become more sophisticated and efficient-have enable development of new food uses of the starch.

Edible films must be produced from materials with film forming ability [12] and the starch looks suitable for it. Then, the use of non-conventional starches, such as those isolated from roots and tubers, could provide new options for such use [11]. More so than, starches have specific functional properties defined by their botanical source.

The edible film concept represents a stimulating route for to create new packaging materials. This is because edible films and coatings are available with a wide range of properties that can help to alleviate many problems encountered with foods. The mainly properties of the edible films can be pictured as: -carrier of ingredients that can proportion a special property to the food, or -by itself functional properties; such as mechanical resistance, solubility, transparency. The first is by addition of antimicrobials, flavor, phytochemicals, preservatives, vitamin and minerals among others, and the second one by addition of plasticizers, composite, or using chemical and/or physical modified starch or with high amylose. Consequently, due of its ubiquity, low cost, renew ability, good mechanical properties, and easily handling, starches from different sources have been used to produce biodegradable films to partially or entirely replace plastic polymers [13]. Even more, starch also can provide a selective barrier to oxygen and carbon dioxide and the necessary supporting matrix for edibles films and coating. Garcia et al. [1] have shown that CO2 and 02 permeability's of films without plasticizer were significantly higher $(p<0.05)$ than plasticized films. In this context, starch, has been recently renewed due to its abundance, low-cost, biodegradability, relatively easy to handle, and capacity of forming thermoplastic materials and the possibility of processing, using conventional polymer processing equipment.

In food technology as previously mentioned, the mainly used starches are isolated and purified from cereals, roots and yams.

At the Andeans region, and also at tropical areas of the world there are numerous starch rich crops, that are yet unexploited. Pseudo cereal (amaranth and quinoa), Musa genus, pulses and roots and tubers are among them. All of these starches have their inherent functional properties that can be investigated and characterized for its uses in edible films with distinctive functional properties. In this sense, it had elaborated films using native starch isolated and purified from roots and tubers [14]. En their work starch-based films were processed by casting solutions prepared with each starch, glycerol, and distilled water. Starch suspensions were gelatinized by heat, degassed, poured in plates and dried. In the films, studies done were water vapor, oxygen and carbon dioxide permeability, and mechanical properties in terms of tensile strength and crystallinity patterns. Authors have reported that the starch isolated from Ipomoea batatas and Colocasia esculenta exhibited polymorphism ApB type X-ray pattern, Xanthosoma sagittifolium, an A-type X-ray pattern, and Arracacia xanthorriza and both Dioscorea trifida, B-type patterns; while starch based films had all a B-type X-ray pattern. Studies of [15] using debranched Naegeli dextrins from different $A$ and B native starches have indicated that the A-type starches had branch points scattered in both amorphous and crystalline regions and B-type starch had most branch points clustered in the amorphous region. It can be supposed that the effect of gelatinization, and the mobility of polymer by the addition of plasticizer to have induced the formation of amorphous zone, and for hence, the B type films.

As expected, the potential for films using native starch isolated and purified from roots and tubers are more in the area of decreasing gas exchange rather than retardation of water loss due to their hydrophilic nature. Films from these non-conventional starch sources with barrier and mechanical characteristics tailored for specific uses can be of interest as plastics for the food industry and results may be of significance also, for starch-based foams. Furthermore, the numerous potential applications of natural polymers stimulated the study with edible films based on cassava starch. Films from native cassava starch had good flexibility and low water permeability, indicating its potential application [5].

\section{Waxy Versus- amylo type starches}

One consideration that have to be done for the preparation of edible films and coatings is regard the presence or absence of amylose in the granular structure. It has been pointed out that 
high amylose starch is a good source for new food applications $[16,17]$. Film and cover have functional barriers that depend of the nature of the polymer where their come from. Typically, the starch granule is composed of $25 \%$ amylose and $75 \%$ amylopectin. Edible films require starches with a high amylose content $(\geq 70 \%)$. The amylopectin molecule cannot adequately forms films; the branched structure imparts poor mechanical properties to the film, reducing its tensile strength and elongation [18,19]. According to Guibert \& Gontard [20], amylose is responsible for the film-forming capacity of starch. Consequently, authors suggesting that free-standing films can be produced from aqueous solution of gelatinized amylose and drying. It has been postulated [21] that films from starch with more amylose are opalescent and thicker, and with less amount, they are transparent and thinner. Mark et al. [22] have reported that films produced from high amylose corn starch (71\% amylose) have no detectable oxygen permeability at $\mathrm{RH}$ levels less than $100 \%$. This was true for both unplasticized and plasticized (16\% glycerol) films. Additionally, Krogars et al. [23] have established that films of high-amylose corn starch or potato starch was more stable during aging, lost little of their elongation and had not or a slight increasing in tensile strength. In other work, [21] it has measured the effect of the starch type on the physico-chemical properties of edible films. They have pointed out that higher amylose content in films induces higher moisture sensitivity, and thus affects the mechanical, and barrier properties. They also affirm that films made from potato starch constitute a greater barrier for oxygen and water vapor, though they have weaker mechanical properties than wheat and corn starch films. Same authors sustain that starch species with higher amylose content have lower wet-ability properties, and better mechanical resistance, which strongly depends on the water content due to the hydrophilic nature of starch films, Then, they could be used for products with higher water activity, such as cheese, fruits and vegetables. Colussi et al. [24] have shown that low amylose rice starches, whether native or acetylated, did not form films with desirable characteristics. Contrarily, Gutierrez et al. [25] showed that high quality edible films can be prepared from modified 80:20 waxy:normal corn starch, and demonstrated their potential as a coating or packaging material in the food industry.

The effects of water and glycerol contents on oxygen permeability of starch polymer films were also investigated by [26]. Authors report that under ambient humidity both amylose and amylopectin films were excellent oxygen barriers, as good as the commercial ethylene vinyl alcohol film which was studied as a reference material. They also have reported that the film permeability's were determined by water content; below $15 \%$ water both starch films were good oxygen barriers, above $20 \%$ water the barrier property was lost.

\section{Plasticizer}

Plasticizing agents is among the factors that can also substantially modify the ultimate properties of the film. Other factors are, film-forming technology, solvent characteristics, temperature effects, solvent evaporation rate, coating operation usage conditions of the film (relative humidity, temperature) [27], and type of matrix; as was previously pointed out.

Starch have evident film forming properties at the slurry, as function of the botanical source from they came from. The amylose content and presence of others constituents are account as responsible for this role. Then, could exists differences in the functional properties of the films and covers when using different types of starch. As well as, the form of the starch (native or modified) also exerts important function on them. Despite of it, native and modified starch by itself present poor mechanical properties regarding process-ability and end-use application, since the fragility and brittleness exhibited during the thermosformation can limit their potential for application. Moreover, the films elaborated from starch have disadvantages due its strong hydrophilic behavior, which makes them sensitive to contact with water, and with inferior mechanical properties (low flexibility, yielding brittle materials), as compared to plastic films [28,29]. So, the addition of plasticizers which, through intermolecular interactions with the polymer matrix, must improves the characteristics and properties of films [30] and provide the necessary workability to it.

A plasticizer could be defined in the food technology argot as a substance (usually hydrophilic compounds) added to a forming solution in order to produce or promote the film malleability and plasticity and reduce breakability. The decisive role of plasticizers is to enhance the flexibility and process-ability of starch by reducing the strong intermolecular interactions between starch molecules. As a result, the mobility of polymeric chains increases, which improves the flexibility, extensibility and ductility of plasticized films [31], overcoming the starch films brittleness [32]. The plasticizers must be compatible with the film-forming polymers, reduce cumulative intermolecular forces, increase intermolecular spacing and the mobility of polar polymer chains and reduce polymer chain cohesiveness upon incorporation [33]. The best plasticizer for starch is water at a concentration of $45 \%$. Garcia et al. [1] also have postulated that the addition of plasticizers to improve properties of starch-based films by avoiding pores and cracks.

Hydrophilic compounds, such as polyols glycerol, sorbitol and poly (ethylene glycol) are commonly used as plasticizers in hydrophilic film formation. Plasticizers with characteristics such as, small size, high polarity, more number of polar groups per molecule, and greater molecular dimensions between polar groups within a molecule generally impart greater plasticizing effects on a polymeric system. However, the selection of a plasticizer for a specified system is normally based on the compatibility and permanence of the plasticizer, and the desired physical properties in the films $[31,33]$. 
During the initial hydration from the dry state, a biopolymer film experiences improved elasticity as a result of extensive connections established between water and polymer. With increasing hydration, film elasticity and cohesiveness decrease progressively because water-polymer interactions developed to the detriment of polymer-polymer bonds. In a ternary system, water plasticizer-polymer, the presence of a second plasticizer normally has a deciding factor on the plasticizing action of the primary one. It reduces the cumulative intermolecular forces polymer-water, increase the intermolecular spacing and the mobility of the polar polymer chains and reduce polymer chain cohesiveness upon incorporation [33].

Sanyang et al. [34], pointed out that the most commonly used plasticizers for starch films are glycerol and sorbitol. They assayed both plasticizers on sugar palm starch to elaborate films. The results demonstrated that plasticizer type and concentration affect the film thickness, density, moisture content, solubility, swelling capacity and water absorption. In divergence Guilbert \& Gontard, [20] shown that the increment of the plasticizers concentration decreases the density and water absorption of the films. Bertuzzi et al. [35] have pointed out that films elaborated with corn starch exhibited an increase in elongation and a decrease in tensile strength with increment of the glycerol concentration, beside some fissures were detected in the dry films, possible due to phase separation (starch-glycerol) phenomena. Film crystallinity is related to the reorganization capacity of the polymer chain, and thus the relative film crystallinity should increase with plasticizer content (glycerol and water). According to Bourtoom [18], the color of biodegradable film from rice starch-chitosan was more affected by the concentration of the plasticizer used, than by its type. They also mentioned that glycerol and sorbitol are compatible with amylose and improved mechanical properties of films, by decreasing intermolecular attraction and interfering with the amylose packing. In this context, García et al. [1] have shown that amylomaize films plasticized with glycerol had lower 02 permeability, than normal corn starch films.

It has been postulated that sorbitol bring in the films high thickness, density and thermal stability, whereas, glycerol increments the moisture content and solubility. Films containing sorbitol show lower gas permeability than those containing glycerol $[1,34,36]$. Studies achieved by Bourtoom [18] have demonstrated that sorbitol provide to the films with highest mechanical resistance, but the poorest film flexibility. Rompothi et al. [37] whom have also assayed the glycerol and sorbitol as plasticizer have concluded that glycerol provided better plasticizer, efficiency than sorbitol. Authors also have postulated that increasing plasticizer concentration tended to decrease tensile strength, elastic modulus and oxygen permeability; but increase elongation $(\% \mathrm{E})$, solubility, water vapor permeability and seal strength as function of starch type and concentration. According to Borges et al. 2015 [38], rice starch and glycerol result as the most suitable starch and plasticizer for the preparation of flexible films with potential for coating foods. In contrast, glycerol and polyethylene glycol plasticized films exhibited flexible structure; however, the mechanical resistance was low, while inversely affecting the water vapor permeability. Though, Krogars et al. [39] have defined that a 1:1 combination of glycerol-sorbitol as plasticizer for maize starch films was found to be more stable than using glycerol and sorbitol separately.

\section{Starch Edible Films as Carriers of Ingredients}

The use of antimicrobial compounds in edible coatings of proteins, starch, cellulose derivatives, chitosan, alginate, fruit puree, and egg albumin has been successfully performed [40, 41]. It is because of that starches can produce edible films and coating, that can be carriers of numerous substance to improve the quality of the food where they are applied, improving its functional properties. Indeed, the incorporation of natural additives into food matrices can be achieved through the use of them. Such films may function as an encapsulater to deliver different constituents to food. They can encapsulate flavor and color (pigments), nutritional ingredients, antioxidants, antimicrobial agents, ions, stopping several reactions on superficies of food. They represent the best alternative for incorporating protective antimicrobial and antioxidant agents onto the surface of food.

In this context, several researches have been done. Piñeros-Hernández et al., [42] have successfully incorporated polyphenols-rich rosemary extracts within cassava starch films producing an active UV-blocking food packaging with antioxidant properties.

Chandra Mohan et al. [43] have produced and optimized spice fused tamarind seed starch edible films for meat packaging. The authors have pointed out that when the optimized edible tamarind seed starch film was mixed with a minimum inhibitory concentration of the mixture of cinnamon and cloves shown an improved antioxidant and antibacterial properties. OlléResa et al. [44] have used natamycin and nisin inside the edible films to improve the microbiological stability of cheese. They conclude that film with natamycin and nisin is an extremely effective method to control the population of microorganisms present in both the cheese and the film, enabling to offer the consumer a safer product. Due that Lactobacillus plantarum inhibit the growth of pathogens, Ghosh et al. [45], have report the incorporation of L. plantarum within a starch matrix using sucrose as a protectant and glycerol as a plasticizer. Antimicrobial activity assays showed that films with L. plantarum incorporated have inhibited E. coli moderately, and when assisted with starch-degrading $\alpha$-amylase, E. coli growth was reduced significantly. These 
findings demonstrate the potential of this natural antipathogenic film to be applied as an edible coating for food and as a second layer with traditional synthetic thermoplastics to improve food shelf-life. Gutierrez T [46] have recommended the employment of films with the addition of blackberry. This film that have been assayed on in vitro cells, had lower digestibility rate, anti-inflammatory activity and higher cell viability, which is encouraging in the development of edible films with nutraceutical properties. Terassi Bersaneti et al. [47] have used fructo oligo saccharides (FOSs) as a functional ingredient in the elaboration of cassava starch edible films. These films had a good appearance and were easily removable from the plates without bubbles or cracks. Beside it phytochemical properties, the FOSs exerted a plasticizing effect on the starch films and decreased their glass transition temperature. The addition of FOSs resulted in higher solubility and elongation and a decreased water vapor permeability of the films. FOSs were shown to be a promising ingredient for use in edible starch films.

Praseptiangga et al. [48] in their studies, cassava starchbased have elaborated an edible coating incorporated with lemongrass essential oil (1\%) and applied by spraying and dipping methods to preserve papaya MJ9 during storage at room temperature. The addition of lemongrass essential oil (1\%) significantly inhibited the microbial growth on papaya MJ9 by reducing the account of total yeast and mold, when comparing to the control. They also shown that the weight loss, total soluble solid, vitamin C, and total titratable acid had lower values, than control. These results indicate that cassava starch-based edible coating incorporated with lemongrass essential oil (1\%) can be used as an alternative preservation for papaya.

In order to reduce additives incorporated to the foods. Ferreira Saraiva et al. [49] have done a study developing active edible films of potato starch, inverted sugar and sucrose; using potassium sorbate and citric acid as preservative to coat mini panettones. Authors report that from 16 to 24 days $\left(35^{\circ} \mathrm{C} / 60 \%\right.$ $\mathrm{RH})$, panettones without coating and without additives (controls) showed growth of mold/yeast; while with both additives coating, fungal growth was observed from 40 days. When using potassium sorbate, mold/yeast was not detected until 48 days. During storage, there was reduced water activity, moisture, elasticity and cohesiveness of panettones with additives, while the opposite occurred in controls. The incorporation of food-graded antimicrobial compounds in the packaging films of potato starch coatings in concentrations lower, than those normally used for mini panettones increased up to $130 \%$ their shelf life and may contribute to product loss reduction during storage. Díaz et al. [50] have used edible coating based in Aloe vera gel and cassava starch for coating pieces of artesian costeño cheese. This kind of cheese, due to its procedure as artesian item is susceptible to fast contamination and films with Aloe vera are a solution. Edible coatings of cassava starch matrix carrying fennel oil and acid ascorbic have been applied by Lima et al. [51] to reduce the translucency in fresh-cut pineapple. Adiantum capillus-veneris extract was incorporated in starch based matrix and applied to fresh-cut pear [52]. These results demonstrated that the development of an edible film formulated with A. capillus-veneris extract can be applicable to preserve fresh-cut pear quality. Wheat starchbased films were formulated for packing pistachio kernels Wheat starch bags reduced the rate of oxidation in pistachio kernels. These results suggest that wheat starch-based films are a viable alternative packaging process for pistachio kernels and improvement of shelf life [53].

\section{Composite Films}

Composite films and covers have also been assayed and its functional properties evaluated. Medina Jaramillo et al. [54] have proposed the yerba mate extract as plasticizer to improve the cassava starch-glycerol matrix for preparing edible films. They have concluded that extract led to a decrease in the degradation time of the films in soil, ensuring their complete biodegradability before two weeks and to films stability in acidic and alkaline media. Podshivalov et al. [55] have assessed the microstructure morphology and the functional properties of the gelatin/potato starch/glycerol edible bio-compositefilms varying on them the starch content from 0 to $50 \mathrm{wt} \%$. They found that when the starch content was less than $30 \mathrm{wt} \%$ the phase separation mechanism is nucleation and grow, whereas the starch content upper $30 \mathrm{wt} \%$ then the spinodal decomposition is the dominant mechanism. They also adduce that mechanical properties (strength and elasticity), transparency and film stickiness are severely deteriorated by the increment of starch in the films forming solution. The additions of $\mathrm{ZnO}-\mathrm{N}$ into the starch/gelatin films were investigated by Mehdi Marvizadeh et al. [56]. The results clearly showed that incorporation of ZnO-N effectively increased the hydrophobicity behavior of the biopolymer. Furthermore, significant decreases in the elongation at break and oxygen permeability of the film with the nanoparticles were found compared with the control film. The electromagnetic properties of edible films show that UV light is absorbed with the addition of small amounts of $\mathrm{ZnO}-\mathrm{N}$ to the biopolymer matrix. In comparison with effects of $\mathrm{ZnO}-\mathrm{N}$ on starch or gelatin alone effects of $\mathrm{ZnO} \mathrm{N}$ is more pronounce on mixed starch/gelatin matrix. These characterizations show that the incorporation of $\mathrm{ZnO} \mathrm{N}$ into starch/gelatin film is an ideal option for the development of nano-packaging for extending shelf life of foods or non-food materials. Soukoulis et al. [57] have assayed native rice and corn starches composited with bovine skin gelatine, sodium caseinate and soy protein concentrate for the fabrication of the edible films inoculated with L. rhamnosus GG pellets as probiotic. The reduction of the amount of probiotic and its viability were significantly lower when using a composted matrix for the 
edible films. The addition of protein to the rice based films was associated with the development of a more compact and cohesive structure, presumably due to the ability of proteins to either interact with starch molecules via hydrogen bonding or hydrophobic interactions thereby reducing the interspaces within the starch matrix. The film's shelf-life ranged between 27-96 and 15-24 days for systems stored at fridge or room temperature conditions respectively. Carrageenan, extracted from Mastocarpus stellatus seaweeds as an alternative to commercial kappa carrageenan was used by Larotonda et al. [58] for produce edible film. The films forming solutions of rice starch and carrageenan showed rheological properties comparable to those of commercial kappa carrageenan-based solutions. Films formulated with rice starch-carrageenan show significantly enhanced UV barrier, oxygen barrier, and hydrophobic properties. In order to study the mechanical and functional properties of films based in rice starch-tcarrageenan-stearic acid-glycerol, Thakur et al. [59] have elaborated films with different concentration combination of the three first leaving the glycerol a constant concentration of $1 \%$. The tensile strength and elongation-at-break of film were improved significantly $(\mathrm{p}<0.05)$ when kappa carrageenan was increased in the film matrix. When adding surfactant and increasing the glycerol concentration film with good physical, mechanical and barrier properties were obtained. Results reveal that molecular interactions between rice starch and kappa carrageenan have a great impact on the film properties confining the compatibility and miscibility of mixed polysaccharide.

Slavutsky \& Bertuzzi, [60] had used lipid for elaboration of nanolaminated edible films, the application of the nanolamines produce important reduction in film water adsorption. The water vapour transport was controlled by water diffusion through the hydrophobic nanolayers. Authors have declared that nanolamination of edible films improved the water barrier properties of hydrophilic films by combining starch with lipids materials at nanometric scale. Matta et al. [61] have pointed out that composite starch films with plasticizer and lipid showed lower crystalline-amorphous ratio compared to films without additives.

Gelatin was also assayed by Matta et al. [61] to improve the functional properties of matrix of corn starch to forming films with glycerol or sorbitol as plasticizers. The addition of gelatin significantly had increased the mechanical strength, solubility in water, permeability to water vapor, and thickness of the biofilms, while also decreasing the opacity. These films forming solutions also was applied onto red Crimson grapes, to cover it. The application improved the appearance of the coated grapes after 21 days' storage under refrigerated conditions, which had lower weight loss than the control group.
Sensory evaluation showed that all the coatings did not affect acceptability scores.

The research of Sessinia et al. [62] shown that the reduction of the inter- and intra-molecular bonds interaction within the polymer matrix due to glycerol presence leads to a decrease of the thermal stability of the whole system. Author prepared edible films using native potato starch plasticized with glycerol and reinforced with catechin and starch nanocrystals obtained by acidic hydrolysis from waxy maize starch granules. All the edible films were fully disintegrated in compost conditions suggesting their possible applications as biodegradable edible films for packaging.

Alginate, starch, and carboxymethy cellulose were successfully employed to fabricate an edible film as antimicrobial and anti browning for coating bamboo shot. The film prepared from alginate and starch (1:2) blend with carboxymethy cellulose have evinced: lower water vapor permeability, moisture absorption, water solubility, and elongation capacity, and high breakage strength with less yellowness and lighter film, than the control. Surface characteristics showed the uniformity of film; as well as, its thermal stability. The addition of starch and carboxymethy celullose imparted an important influence on the barrier, and mechanical properties of the resulted composite films. Coating of bamboo shoot resulted in less water loss, lowered the color change $(\Delta \mathrm{E})$ value and reduction in surface microbial count, which could be attributed to incorporation of antioxidant and antibacterial extracts in film forming solution [63].

Edible coatings/films were prepared using cassava starch, glycerol, carnauba wax and stearic acid. Those formulation containing $3 \%(\mathrm{w} / \mathrm{w})$ cassava starch, $1.5 \%(\mathrm{w} / \mathrm{w})$ glycerol, $0.2 \%$ $(\mathrm{w} / \mathrm{w})$ carnauba wax and $0.8 \%(\mathrm{w} / \mathrm{w})$ stearic acid, presented films with a cohesive matrix with optimal mechanical properties, such as, barrier to moisture and gas exchange [64].

The effect of surfactant addition on structural, mechanical, optical and barrier properties of corn starch glycerol based films was studied by Rodrigo Ortega et al. [65]. Authors have incorporated sorbitan monopalmitate, monostearate or monooleate (span) into starch-glycerol (1:0.25) with a surfactant: starch ratio of 0.15:1. Despite that incorporation of SPAN 40, 60 or 80 into the corn starch-glycerol film forming dispersions led to different particle size distribution, result shown that the films containing surfactants were less hard, resistant and extensible than surfactant-free films, and also that the surfactants did not notably affect the film gloss and transparency. The use of surfactants in film formulation can be useful to incorporate non-polar bioactive compounds in the aqueous film forming dispersions. In this sense, the obtained results allow to recommend saturated fatty acid 
compounds with higher melting temperature to ensure a finer microstructure in the final film which favor water barrier efficiency.

An innovative approach was performed by Kanmani \& Taik Lim [66], to prepare novel pullulan/starch blended edible films by direct incorporation of multiple probiotic bacterial strains. The results suggest that pullulan and pullulan/starch films can be used as effective delivery and carrier systems for probiotics. The use of guar gum was assayed by Saberi et al. [67] producing starch edible films with appropriate physical and optical characteristics. Cellulose microfibrillated from carrot was also applied by Costa et al. [68], as reinforcement in starch edible films with lower water vapor permeability and higher tensile strength than starch films.

The physicochemical, mechanical, optical and structural properties based on different amylose (mung bean and water chestnut starches) content starch-chitosan films with the addition of hydrophilic glycerol and hydrophobic perilla oil were investigated, and the effects of the starch-chitosan coating on the physicochemical and microbial properties of Mongolian cheese were also evaluated [69]. The properties of edible films based starch-chitosan was influenced by the amylose content and the addition of glycerol or perilla oil. Tensile strength and elongation capacity were positively influenced by the glycerol and negatively by the perilla oil. For water vapor permeability, the presence of the glycerol and perilla oil had a negative effect, whereas the presence of the perilla oil had a positive influence on film forming solution. Moreover, the films showed the surface irregularity increased with the addition of glycerol and perilla oil and there were some Millipore inside the membrane. When the films were coat the surface of the Mongolian cheese to improve the preservation the growth of bacterium and fungi was substantially delayed and the weight loss of cheese was obviously low. The present research can serve as a guide for the use of new coatings for cheese as alternatives to synthetic coatings.

A film elaborated with Chinese herbal medicine-starchchitosan was assayed as coating on citrus fruits by Hucheng et al. [70]. Authors wanted to explore possibilities of using it as a substitute for chemical preservation and bagging. The results suggest that composite coating not only has the same effects on disease resistance and delaying senescence, but also it gives better fruit quality than chemical preservation. Therefore, composite coating could be used as a substitute for chemical and bagging preservation. Starch-chitosan blends were used to produce film in order to evaluate the shelf-life extension of fresh shrimps during chilled storage. Generally, the effect of coating solutions on shrimp shelf-life is positive but in necessary to continue the research to improve the results [71]. Blends of glycerol and polyethylene glycol as plasticizers and glutaraldehyde as cross linking agent have been assayed by Parra et al. [5] in order to determine the mechanical properties and water vapor transmission of the films. A response surface methodology was applied by the authors on the results to identify the blend with the best mechanical properties and lowest water vapor transmission.

Functional properties of blend film composed of 15\% w/w carboxymethyl cellulose / native corn starch was elaborated by Ghanbarzadeh et al. [72]. The addition of carboxymethyl cellulose to starch-glycerol blends improved the moisture resistance of the resulted starch based composites and the films elaborated with addition of $15 \% \mathrm{w} / \mathrm{w}$ of carboxymethyl cellulose decrease the water vapor permeability, the moisture absorption, and solubility in water. The color also is altered as the carboxymethyl cellulose concentration is increased. The plasticizing action of polyethylene glycol was restrained by more than $0.5 \mathrm{~g}$ of glutataraldehyde, due to its cross linking effect in the films. Vásconez et al. [73] have probed the antimicrobial effect of chitosan-tapioca starch based edible coatings and films and, specifically, their capacity to improve the global quality of salmon muscle, as well as the effect of chitosan presence on some physical properties of edible films. The results suggested that the chitosan antibacterial action depended on the technique of application. Chitosan was more effective in the coating solution than in the film matrix. The addition of chitosan to a starch matrix produced less water vapor permeation and reduced solubility of the films in water. These properties might be linked to the higher hydrophobicity introduced by the presence of preservatives. The inclusion of potassium sorbate did not modify solubility, but it did increase water vapor permeability. According to Santacruz et al. [74] the starch source, starch concentration and type of plasticizer were the most important factors to be consider on formulation of edible films based on starch and chitosan. Those factors affect to most of the evaluated film properties, except opacity and elasticity. Stirring time may be a valuable and economic tool to improve elasticity, whereas the use of an appropriate surfactant may help to improve the tensile strength of the starch film.

\section{Use of modified starch to produce bio-films and coating}

The functional properties of starch vary as a function of the amount and conformation of the amylose and amylopectin molecules, the granular structure, and the natures and amounts of other minor constituent present in granules, given to them a wide gamma of uses. Native starches from several botanical sources could be used as raw materials that represent appropriate bio-matrices to contain diverse bioactive substances when formulating composite edible films or foams. However, native starch film application is limited by poor mechanical strength and its efficient barrier against low polarity compound [75]. Moreover, films elaborated from them have disadvantages due its strong hydrophilic behavior, which makes them sensitive to contact with water, 
and with inferior mechanical properties as compared to the non-biodegradable plastic counterpart. Its modification, beside the use of plasticizers and some types of starch and non-amylaceous ingredients shall help them to produce edible and biodegradable films and coating with optimum functional properties. The business of modified starch is an everevolving industry with numerous possibilities to enhance the positive attributes, eliminate the shortcomings of the native, and to generate novel starches which includes new functional and value-added properties as a result of modification and as demanded by the industry [76]. Moreover, the structural conformation of the main polymers that form the starch make possible their modification, addressing them to a specific use. Such modification can be brought about by using chemical, physical, or biological techniques. The chemist modification of frequently uses is the substitution.

Chemical modification changes the character of the starch, for example, rendering them hydrophobic. Some such processes, such as the formation of esters or cross linking are very well known and have been carried out at an industrial level for more than a hundred years. Chemical cross-linking or substitution improves the functional properties of starch in a number of applications. Cross-linking introduces additional covalent bonds (e.g. phosphate or adipate diester linkages) between starch molecules stabilizing and strengthening the granules. Substitution (e.g. oxidation, acetylation or hydroxypropylation) introduces bulky substituents on the starch chains, thereby weakening the granular structure and reducing the extent of amylose and amylopectin crystallization. Moreover, due the high potentially of starch for genetic modification (GM), some researching have be done in this area. Starch GM offer significant advantages as compared to other modification types for example; over the chemical modifications, which are expensive and environmentally hazardous, are replace, and also with GM novel carbohydrates can be produced [77]. In last decade, the modified starch to produce films and coating for stabilize food functional, innocuous and nutritional properties, has took much attention, both at the academic as well as at the industrial level, because these films exhibit dramatic improvement in filming properties without involving any significant increase in cost of production [78].

In this context, modified maize and cassava starches have been used for elaborate coatings in order to avoid the Vitamin A loses during dehydration of slices pumpkin. The application of these starch solutions has produced a uniform film, minimizing carotenoid degradation during pumpkin drying and, as a consequence, resulting in a product that can be considered a good source of provitamin A [79].

Acetylated, cross-linked or oxidized starches, microemulsified beeswax (BW, 0-1 \% w/w), and two natural antimicrobials (lauric arginate $(2000 \mathrm{mg} / \mathrm{L})$ and natamycin
(400mg/L)) was used by Ochoa et al., [80] for preservation of fresh produce. Films made with $1 \%$ beeswax microemulsion shown homogeneous surface and did not show changes in thickness or opacity. Water vapor permeability was reduced; tensile strength and elastic modulus were decreased, whereas elongation at break increased as compared to control. The additive effect showed by the combination of natural antimicrobials incorporated into films with $1 \%$ BW completely inhibited Rhizopus stolonifer, Colletotrichum gloeosporioides, Botrytis cinerea, and Salmonella Saintpaul. These properties of modified corn starch films used as coatings represent an excellent alternative to extend the shelf life of fresh produce.

Gomes et al. [81] have done study to develop and characterize edible films based on the starch phosphates (modified from S. burchelli seeds native starch), with the specific aim to apply these edible films on cherry tomatoes for post-harvest conservation. The authors have concluded that the modification performed on the starch and the glycerol concentration positively influenced the properties of the edible films, allowing for optimal use in post-harvest applications. Similarly, the edible coatings conferred better appearance to the fruits, maintaining their maturation index and firmness up to 21 days at $10 \pm 2^{\circ} \mathrm{C}$ and $80 \pm 5 \%$ relative humidity and providing better post-harvest storage conditions for the cherry tomatoes.

One of the goals of the studies achieved for Pérez et al. [82], was to produce edible films and coating solution using native and modified (cross linked with trimetha phosphate at $0.002 \%$ of degree of substitution) starches from Dioscorea trifida. The native and modified starches were used to formulate coating solution and films with 5\% of D. trifida starch and $1.5 \%$ glycerol. The coating solution was applied avoiding the browning enzymatic reaction in unripe plantain sliced during a week. Significant statistical differences in the film thickness, color profile, deformation, and stress to puncture were found as function of the modification of the starch. The modified starch-based films exhibited higher width and opalescence, but less water retention and higher water permeability and solubility than those formed with native starch. Later, Gutierrez et al. [83] have evaluated the properties of edible, biodegradable films based on native and phosphate cush-cush yam Dioscorea trifida and cassava, plasticized with glycerol, in order to determine its potential applications in the food industry. Authors have postulated the amylose molecules in the cassava starch strongly interacted with glycerol resulting in an increase in the number of hydrogen bonds. This led to a slight shift upwards in the temperature required for the onset of the degradation of the cassava starch-based films, and even higher temperatures for degrading the films based on the modified starches. Films made from phosphated-starches were more hydrophilic, producing an increase in solubility 
and crystallinity than its native counterparts. The authors conclude as a function of the characteristics developed by the cassava films, that they would make good packing materials, while films derived from cush-cush yam are more suitable as food coatings. Far ahead, Gutiérrez et al. [84] have continued to study the structural and mechanical properties of edible films made from native and modified (cross linking) cush-cush yam and cassava starch in order to determine their potential as a replacement for existing synthetic materials used in the food industry. It was reported by the authors that the structure of the materials showed that the gelatinization process of cush-cush yam films was poorer, than that of cassava. The glycerol-starch interaction (glycerol-amylose) was stronger in the films composed of modified starches, and was more marked in cassava based films. All the films studied exhibited promising mechanical properties, with those derived from cush-cush yams showing the highest Young's modulus and resistivity values. Cassava based edible films and films derived from modified starch from both sources showed maximum flexibility, reinforcing the idea that the glycerolstarch interactions are stronger in these materials. Cross linked films tended to be more permeable to water vapor due to their hydrophilic characteristics.

As was postulated by Gutierrez et al. [83], the cross linked modification by phosphatizing with sodium trimeta phosphate (STMP) could improve the films physicochemical properties by reinforcing the hydrogen links inside the films. More studies are required and the potential uses of waxy starches, native and modified should be investigated. In their work [84-86] on films elaborated with native and cross-linked composite corn starch (80:20 waxy: regular), are postulating that this films had highest hydrophilic properties which increased its thickness, permeability and solubility, and with high stability in acidic and alkaline medium. Finally, physicochemical properties and water vapor barrier data of this film denote the strong interaction in the phosphate-starch-plasticizer.

The thermal degradation and dynamic mechanical properties of starch-glycerol based films with citric acid, as crosslinked agent have been described by González Seligra et al. [87]. The cross linked modification of the starch has allowed decreasing water vapor permeability more than $35 \%$, remained amorphous for at least 45 days, as a result of the network formed by the citric acid that avoided starch retrogradation and maintained the degradability in compost, occurring only six days after the films without citric acid.

According to Paz Peña et al. [88], cassava starch enzymatically modified allowed to obtain films with fewer defects and better performance than those made with natural starch. Additionally, thickness was found to be an influential factor, so matrices were developed to analyze its effect, finding that the water vapor permeability decreased by increasing the thickness between 0,15 and 0,17 $\mu \mathrm{m}$. Guimarães et al. [89] have pointed out that the use of coating film with starch nanoparticles and modified atmosphere leads to the preservation of the total antioxidant activity, the volatile and organic acids of fresh-cut carrots.

Gutierrez and González. [90] have verified the effect of pulsed light (PL) treatments as a cross linking method on films made from cassava (Manihot esculenta C.) and taro (Colocasia esculenta L. Schott) starch, plasticized with glycerol. The average molecular weight, contact angle, moisture content, X-ray diffraction pattern, color, and mechanical and micro structural properties were evaluated. Films subjected to PL showed deterioration compared with control films, as demonstrated by an increase in the contact angle, surface roughness, and crystallinity, and a decrease in the tensile strength, transparency, and water content, independent of the amylose content of the starches evaluated. Finally, the surface properties of these materials are defined by intermolecular interactions; such as, van der Waals-type force interactions (hydrogen bond), new bonds (cross linking) formed between the biopolymeric chains (starch), and by breakage of covalent bonds.

Recently, Hu et al. [91] have developed starch films from oxidized potato starch (OPS) with glycerol as a plasticizer at different contents. The OPS films were transparent and flexible and with $19.4 \%$ glycerol exhibited the desirable mechanical properties. They also had excellent anti-leakage ability for vegetable oil, good anti-cross linking ability in saturated formaldehyde vapor, and good stability in acid aqueous medium, but poor stability in alkali aqueous medium. Similarly, Zamudio-Flores et al. [92], have elaborated forming solution for edible films using oxidized oat starch $(0.5 ; 1.0$ and $1.5 \%$ $\mathrm{w} / \mathrm{v}$ with sodium hypochlorite) and their blends with chitosan as matrix, and its rheological properties were analyzed. The authors have reported that mechanical properties of the film indicated that tensile strength and elastic modulus increased in the films when the oxidation level and chitosan addition increased, with no significant differences were observed in percentage elongation at break. They have concluded that the rheological characterization is a fundamental determination to know the viscosity of these solutions before they become films and provides a greater understanding of the structurefunction relationships in polymeric materials.

Biodegradable films from native or acetylated starches with different amylose levels were prepared by Colussi et al, [24]. Authors have characterized the films according to its mechanical, water vapor barrier, thermal, and biodegradability properties. The films from acetylated high amylose starches had higher moisture content and water solubility, than its native counterpart. However, the acetylation did not affect acid solubility of the films, regardless of the amylose content. 
Films made from high and medium amylose rice starches were obtained; however the low amylose rice starches, whether native or acetylated, did not form films with desirable characteristics. The acetylation decreased the tensile strength and increased the elongation of the films. The acetylated starch-based films had a lower decomposition temperature and higher thermal stability than native starch films. Acetylated starches films exhibited more rapid degradation as compared with the native starches films.

Galus et al. [93] have studied the effect of using modified starch (acetylated di-starch phosphate and starch acetate) and maltodextrin (DE 10.2 and DE 15.6) on the properties of soy protein films. Addition of starch and maltodextrin had a significant effect on water vapor adsorption of soy films, and increase of diffusion coefficient from 1.73 to $2.60 \mathrm{~m} 2 \mathrm{~s}-$ 1. Water vapor permeability increased as relative humidity differentials increased and observed results can be correlated with the plasticizing effect of water. All films demonstrated low values of tensile strength $(\sim 1.14-1.96 \mathrm{MPa})$ and elongation at break ( 25.6-34.7and they were opaque and homogenous.

Cassava starch modified enzymatically with Bacillus amyloliquefaciens a-amylase with a degree of modification of $10 \%$ of Dextrose Equivalent was used as a matrix plasticized with $2 \%$ of glycerol to produce coating solution for covers the whole fruits of Hass variety avocados (Persea americana Miller). Once the fruits were cover, it was evaluate its respiration rate, firmness, weight loss and color development, at temperature of $24^{\circ} \mathrm{C}$ and relative humidity of $77.5 \%$. Fruits coated with treatments at 2, 3 and $4 \%$ of cassava starch had positive incidence on quality characteristics, resulting in less weight loss, decreased respiration rate, delayed loss of firmness and conservation of green color as compared to uncoated Hass avocados. The treatment using $4 \%$ of starch, with $94 \%$ water was the most effective one, concerning the variables evaluated, given the fact that it confers the necessary functionality and presentation facilitating and promoting marketing, benefiting producers with the generation of added value and offering high quality products to consumers [94]. In spite of not being a modified starch Tumwesigye et al. [95], showed that the starch extracted from bitter cassava roots offers new possibilities in packaging fresh produce under equilibrium modified atmosphere without compromising their quality.

Qiu et al. [96], have prepared films from corn starch dual modified in two ways: cross-linked-esterified (CEF) and esterified-cross-linked (ECF), and comparing with its native counterpart functional and mechanical properties. Compared to native starch film, the CEF and ECF showed improved transparence $(77.59 \%$ and $74.39 \%$ respectively) with compact structure, lower crystallinity $(6.5 \%$ and $7.4 \%$ respectively). Results of mechanical test indicated that structure of ECF was more flexible than CEF, whereas tensile strength was high in CEF. Consequently, dual modification could be an effective method to adequate properties of starch films for specific processing requirements.

According to Wogguma et al. [97], biodegradable films elaborated from dual-modified rice starch (hydroxy propylated with $6-12 \%$ of propylene oxide, followed by cross linking with $2 \%$ sodium trimeta phosphate and a mixture of $2 \%$ sodium trimeta phosphate (STMP) and 5\% sodium tripoly phosphate (STPP)), showed an increase the tensile strength, elongation at break and film solubility. Author have also pointed out, that transparency value and crystallinity of the film has decreased as a function of increment of the propylene oxide concentration, however the water vapor permeability of the films did not significantly change. In addition, they have also found that the films cross linked with $2 \%$ sodium trimetaphosphate demonstrated higher tensile strength, transparency value and lower water vapor permeability, than the films cross linked with a mixture of 2\% STMP and 5\% STPP. The crystallinity of the films with $2 \%$ STMP were higher than the DMRS films with a mixture of $2 \%$ STMP and $5 \%$ STPP.

Waxy corn starch (amylopectin) and three of its chemical derivatives: acetylated cross-linked, oxidized, and octenylsuccinylated were used together with additives such as Tween 80 , sorbitol, and beeswax suspension or safflower oil to test their effect on film-forming solutions and films [98]. Films prepared with oxidized starch and beeswax exhibited the best reorganizing capacity of film forming solution, resulting in less soluble, highly transparent and less permeable, than the other two film forming solution from modified starches. On the other hand, the acetylated cross-linked film forming solution shown an opposite trend, which was attributed to a more open film structure. These results contribute to understand the molecular interactions of waxy starch molecules in film forming solution which may be useful to design tailored coatings.

As an application in the field food preservation, solutions of gamma irradiated plasticized starch / polivinyl alcohol blends in the presence of chitosan, as an antimicrobial material, were used on Mango fruits by surface coating [99]. Mango fruits coated with the gamma irradiated plasticized starch /polivinyl alcohol blend shown high stability in regards to weight loss, rate of reaction, tensile strength and elongation at break, than the pure gamma irradiated plasticized starch. The results showed that this technique would provide suitable materials for food preservation that withstanding temperature and stresses.

\section{Conclusion}

Edible films or coatings are as a thin layer elaborated from proteins, polysaccharides and/or lipids, which can be 
consumed, coated on a food or placed as barrier between the food and the surrounding environment. The terms films and coatings have been used interchangeably, however the films are free standing, whereas, coatings are formed directly on the food product. It's most important functionalities include control of mass transfers, mechanical protection, and sensory appeal.

Last decade, the native starch has been took in account for replacement of synthetic polymers in films and coating elaboration, due to its abundance, low-cost, biodegradability, relatively easy to handle, and capacity of forming thermoplastic materials by using plasticizers and blend composites and its possibility of processing, using conventional polymers processing equipment. Since native starch by itself can not to develop the satisfactory functional properties as films, even complemented with the plasticizer or composite, in order of substantially modify its ultimate properties, it has been considered the use of modified starch.

The best plasticizer for starch is the water at a concentration of $45 \%$, but it is not enough for consolidates the functional properties of the films, for this reason, is necessary to use plasticizers, such as; hydrophilic compounds or polyols (glycerol, sorbitol and poly (ethylene glycol)). The decisive role of plasticizers is to enhance the flexibility and processibility of starch by reducing the strong intermolecular interactions between starch molecules, increasing its mobility, which improves the flexibility, extensibility and ductility of plasticized films.

Native starch, even using plasticizer, might not extensively add the characteristics functional barriers that must have the films or coatings, due they have several drawbacks associated to their hydrophilic properties that limit its function as barrier. At that point, it has been used native starch reinforced with other materials; such as, protein, lipid, waxes, gum, chitosan, catechin micro fibrillated cellulose, among others. All of the starch combination with other materials are called composites. However, in many cases its use has been unsuccessful, then research has been oriented towards the use of modified starches. The modified starch could be a solution, in order to reach those barrier properties that made them applicable to the function desired. Structural differences between the two main polymers that form the starch granules make, possible their modification. The modification of the native starch properties addressing them to a specific use can be brought about by using chemical, physical, or biological techniques, which may improve or introduce the desire functionality in their structure.

Films and covers have functional barriers that depend of the nature of the polymer where their come from. In this framework, it has been reported by some authors that films and coating elaborated with starch with high amylose content have good functional properties. However, some contradictory data have been found, indeed, some research shown that high quality edible films can be prepared from modified 80:20 waxy: normal corn starch. The mechanical performance of the edible films was improved using nano-reinforced gelatinized starch, also these films were fully disintegrated in compost conditions suggesting their possible applications as biodegradable edible films for packaging.

Films from crosslinked yam starch tend to be permeable to water vapor, due to their hydrophilic characteristics. Films elaborated with mix of corn starch (waxy and regular) phosphated have higher hydrophilic properties, which increased its thickness, permeability, solubility, and stability in acidic and alkaline medium as compared to those of its native counterpart.

The acetylated starch-based films shown stability to the decomposition by temperature; however, they are quite sensible to degradation.

Rice starch dual modified (hydroxypropylatedcrosslinking) produce films with strong tensile strength, elongation at break and solubility, while the transparency value decreased, as function of increment of concentration of the propylene oxide. The sequence of modification procedure also has an impact on the final modification degree, resulting in structural differences in the starch films; for example, in esterified-cross-linked corn starch film, the tensile strength was higher and less flexible, than the films elaborated with corn starch esterified-cross-linked. The addition of modified starch (acetylated di-starch phosphate, starch acetate and maltodextrin) affects the performance of soy films. All soy films with the addition of these modified starches demonstrated low values of tensile strength, elongation at break, and they were opaque and homogenous. The use of modified starch has also shown improving in the films functional properties for specific uses, and it is a function of the type of modification, sequence of it and botanical source. Some of them improve the mechanical properties, and crystallinity, but has detrimental effect on the transparency or water permeability.

\section{References}

1. García MA, Martino MN, Zaritzky NE (2000) Lipid addition to improve barrier properties of edible starch-based films and coatings. Food Chemistry and Toxicology 65(6): 941-947.

2. Pavlath AE, Orts W (2009) Edible films and coatings: why, what, and how? In: Embuscado ME and Huber KC (Eds.), Edible films and coatings for food applications. Springer Dordrecht Heidelberg London, New York, USA, pp.1-26

3. FNR 2005-2014. Broschüre der FNR: 2005. Biokunststoffe. Bioenergy.

4. Manjure S (2011) PLA for Paper Coating, bioplastics. Magazine 6(05): 34-37.

5. Parra DF, Tadini CC, Ponce P, Lagão AB (2004) Mechanical properties and water vapor transmission in some blends of cassava starch edible films. Carbohydrate Polymer 58: 475-481. 
6. Shannon JC., Garwood DL (1984) Genetics and physiology of starch development In: Whistler RL, Be Miller JN, Paschall EF (Eds.), Starch: Chemistry and Technology, San Diego Academic Press, pp. 26-86.

7. Morrinson WR., Karkala J (1990) Methods in Plant Biochemistry. 9 Starch In: Dey PM, (Eds.) Vol.2. Carbohydrates. Academic Press, San Diego, pp. 324-347.

8. Trevor L. Wang, Tanya Ya Bogracheva, Cliff L Hedley(1998) Starch: as simple as A, B, C?. Journal of Experimental Botany 49(320): 481-502.

9. Morrison WR (1981) Starch Lipids: A Reappraisal. Starch/Stärke 33(12): 408-410.

10. Eliasson AC (1994) Interaction between starch and lipids studied by DSC. Thermochimica Acta 246(2): 343-356.

11. Pérez E, Rolland-Sabaté A, Dufour D, Guzmán R, Tapia M, et al. (2013) Isolated starches from yams (Dioscoreasp) grown at the Venezuelan Amazons: Structure and functional properties. Carbohydrat Polymers 98(1): 650-658.

12. Bourtoom T (2008) Edible films and coatings: characteristics and properties. International Food Research Journal 15(3): 237-248.

13. Xu XY, Kim KM, Hanna MA, Nag D (2005) Chitosan-starch composite film: preparation and characterization. Industrial Crops and Products an International Journal 21: 185-192.

14. Tapia MS, Pérez E, Rodríguez PE, Guzmán R, Ducamp-Collin MN, et al. (2012) Some properties of starch and starch edible films from underutilized roots and tubers from the Venezuelan Amazons. Journal of Cellular Plastic 48(6) 526-544.

15. Zeng J, Li G, Gao H, Ru Z (2011) Comparison of A and B starch granules from three wheat varieties. Molecules. 2011; 16: 10570-10591.

16. Pérez E, Gibert O, Rolland-Sabaté A, Segovia X, Sánchez T, et al. (2011) Evaluation of the functional properties of promising Dioscoreatrifida L. waxy starches for food innovation. International Journal of Carbohydrate Chemistry 1-7

17. Sárka E, Dvorácek V (2017) Waxy starch: as perspective, raw materia (a review). Food hydrocolloids 69: 402-409.

18. Bourtoom T (2008b) Plasticizer effect on the properties of biodegradable blend film from rice starch-chitosan. Songklanakarin Journal Science Technology 30(Suppl 1): 149-165.

19. Dhall RK (2013) Advances in edible coatings for fresh fruits and vegetables: a review. Critical Reviews in Food Science and Nutrition 53(5): 435-450.

20. Guilbert S, Gontrad (2005) Agro-polymers for edible and biodegradable films. Review of agricultural polymeric materials, physical and mechanical characteristics. In: Hann JH (eds.), Innovation and Food Packaging, Elsevier Academic, England Chapter 4.16, pp. 263-276.

21. Basiak E, Lenart A. Debeaufort F (2017) Effect of starch type on the physico-chemical properties of edible films. International Journal of Biological Macromolecules 98: 348-356.

22. Mark AM, Roth WB, Mehltretter CL, Rist CE (1966) Oxygen permeability of amylomaize starch films. Food Technology 20: 75-80.

23. Krogars K, Heinämäki J, Karjalainen M, Rantanen J, Luukkonen P, et al. (2003a) Development and characterization of aqueous amyloserich maize starch dispersion for film formation. European Journal of Pharmaceutics and Biopharmaceutics 56: 215-221.

24. Colussi R, Pinto VZ, El Halal SL, Biduski B, Prietto L, et al. (2017) Acetylated rice starches films with different levels of amylose: Mechanical, water vapor barrier, thermal, and biodegradability properties. Food Chemistry 221: 1614-1620.

25. Gutiérrez TJ, Tapia MS, Pérez E, Famá L (2014) Edible films based on native and phosphated 80:20 waxy: normal corn. Starch-Starch 67(12):90-97.

26. Forssell P, Lahtinen R, LahelinM, Myllärinen P (2002) Oxygen permeability of amylose and amylopectin films. Carbohydrate Polymers. 47(2): 125-129.

27. Guilbert S, Gontard N, Cuq B (1995). Technology and applications of edible protective films. Packaging Technology and Science 8(6): 339346.

28. Avella M, De Vlieger JJ, Errico ME, Fischer S, Vacca P et al., (2005) Biodegradable starch/clay nano-composite films for food packaging applications. Food Chemistry; 93(3): 467-474.

29. Faria FO, Vercelheze AES, Mali S (2012) Physical properties of biodegradable films based on cassava starch, polyvinyl alcohol and montmorillonite. Química Nova 35(3): 487-492.

30. Dean KM, Petinakis E, Goodall L, Miller T, Yu L, et al. (2011) Nanostabilization of thermally processed high amylose hydroxyl propylated starch films. Carbohydrate Polymers 86(2): 652-658.

31. Cheng LH, Abd Karim A, Seow CC (2006) Effects of Water-Glycerol and Water-Sorbitol Interactions on the physical properties of konjac glucomannan films. Food Science 71(2): E62-E67.

32. Adeodato Vieira MG, Altenhofen da Silva M, Oliveira dos Santos L, Masumi Beppu M (2011) Natural-based plasticizers and biopolymer films: A review. European Polymer Journal 47(3): 254-263.

33. Cheng LH, Abd Karim A, Norziah H, Fazilah A, Seow CC (2006) Effects of water-glycerol and water-sorbitol on physical properties of konjac glucomannan films Journal of Food Science 71(2):E62 - E67.

34. Sanyang ML, Sapuan M, Jawaid M, Sahari J (2015) Effect of glycerol and sorbitol plasticizers on physical and thermal properties of sugar palm starch based films. Recent Advances in Environment, Ecosystems and Development. In: Proceeding of the $13^{\text {th }}$ International Conference on environment, ecosystems and development (EED ‘15), Malaysia, 2015.

35. Bertuzzi MA, Gottifredi JC, Armada M. Mechanical properties of a high amylose content corn starch based film, gelatinized at low temperature. Braz. Journal of Food Science and Technology(3): 219-227.

36. Laohakunjit N, Noomhorm A (2004) Effect of plasticizers on mechanical and barrier properties of rice starch film. Starch 56(8): 348-356.

37. Rompothi O, Pradipasena P, Tananuwong K, Somwangthanaroj A, Janjarasskula T (2017) Development of non-water soluble, ductile mung bean starch based edible film with oxygen barrier and heat sealability. Carbohydrate Polymers 157(10): 748-756.

38. Borges JA, Romani VP, Cortez-Vega WR, Martins VG (2015) Influence of different starch sources and plasticizers on properties of biodegradable films. International Food Research Journal 22(6): 2346-2351.

39. Krogars K, Heinämäki J, Karjalainen M, Niskanen A, Leskelä M, et al. (2003b) Enhanced stability of rubbery amylose-rich maize starch films plasticized with a combination of sorbitol and glycerol. International Journal of Pharmacology 251(1-2): 205-208.

40. Valencia-Chamorro SA, Palou L, Delŕio MA, Pérez-Gago MB (2011) Antimicrobial edible films and coatings for fresh and minimally processed fruits and vegetables: A review. Critical Reviews in Food Science and Nutrition 51(9): 872-900.

41. Poonia A (2016) Antimicrobial edible films and coatings for fruits and vegetables. In: Exploring the Nutrition and Health Benefits of Functional Foods Pp. 301-319

42. Piñeros-Hernandez D, Medina Jaramillo C, López-Córdoba A, Goyanes S (2017) Edible cassava starch films carrying rosemary antioxidant extracts for potential use as active food packaging. Food Hydrocolloids 63: 488-495. 
43. Chandra Mohan C, Rakhavan KR, Sudharsan K, Radha krishnan K, Babuskin S, et al. (2016) Design and characterization of spice fused tamarind starch edible packaging films. LWT - Food Science and Technology 68: 642-652.

44. OlleResa CP, Gerschenson LN, Jagus RJ (2016) Starch edible film supporting natamycin and nisin for improving microbiological stability of refrigerated argentinian Port Salut cheese. Food Control 2016: 59: 737-742

45. Ghosh A, Gupta T, Swaminathan J, Wright D (2015) Mechanical and anti-pathogenic characterization of starch-based materials. Polymer Testing 43: 78-82.

46. Gutierrez T (2017) Surface and nutraceutical properties of edible films made from starchy sources with and without added blackberry pulp. Carbohydrate Polymers 165: 169-179.

47. Bersaneti GT, Mantovan J, Magri A, Mali S, Celligoi MA (2016) Edible films based on cassava starch and fructooligosaccharides produced by Bacillus subtilis natto CCT 7712. Carbohydrate Polymers 151: 11321138.

48. Praseptiangga D, Utami R, Khasanah LU, Evirananda IP, Kawiji (2016) Effect of cassava starch-based edible coating incorporated with lemongrass essential oil on the quality of papaya. IOP Conference Series: Materials Science and Engineering 176 (1): 012054

49. Ferreira Saraiva LE, de Oliveira Melo Naponucena L, da Silva Santos V, Dantas Silva RP, Oliveira de Souza C, et al. (2016) Development and application of edible film of active potato starch to extend mini panettone shelf life. LWT - Food Science and Technology 73: 311-319.

50. Díaz L. Reales J, Torres C (2017) Measurement of the transmittance of edible films of aloe vera (barbadensis miller) and cassava starch using optical fibers trifurcated Journal of Physics: Conference Series 792(1): 012023

51. Lima RP, Silva S, Dantas RL, Dantas AL, Sousa ASB, et al. (2016) Using digital image processing for e valuation of translucency in fresh-cut 'Pérola' pineapple coated with biofilms. Acta Horticulturae 1141: 311 318.

52. Hashemi SMB, ZahabiN, Rezaee Z, Maherani Z, Boghori P, et al. (2016) Evaluation of a Starch-Based Edible Film as Carrier of Adiantum Capillus-Veneris Extract to Improve the Shelf Life of Fresh-Cut Pears. Journal of Food Safety 36(3): 291-298.

53. Javanmard M, AhangariR, Tavakolipour H (2011) Effects of wheat starch edible films on rancidity and moisture uptake of pistachio kernels as a new package. Journal of Food Process Engineering 34(4):1156-1171.

54. Medina Jaramillo C, Gutiérrez TJ, Goyanes S, Bernal C, Famá L (2016) Biodegradability and plasticizing effect of yerba mate extract on cassava starch edible films. Carbohydrate Polymers 151(20): 150-159.

55. Podshivalov A, Zakharova M, Glazacheva E, Uspenskaya M (2017) Gelatin/potato starch edible biocomposite films: Correlation between morphology and physical properties. Carbohydrate Polymers 157: 1162-1172.

56. Marvizadeh MM, Oladzadabbasabadi N, Mohammadi Nafchi A, Jokar M (2017) Preparation and characterization of bionanocomposite film based ontapioca starch/bovine gelatin/nanorod zinc oxide. International Journal of Biological Macromolecules 99: 1-7.

57. Soukoulis C, Singh P, Macnaughtan W, Parmenter C, Fisk ID (2016) Compositional and physicochemical factors governing the viability of Lactobacillus rhamnosus GG embedded in starch-protein based edible films. Food Hydrocoll 52: 876-887

58. Larotonda FDS, Torres MD, Gonçalves MP, Sereno AM, Hilliou L, (2016) Hybrid carrageenan-based formulations for edible film preparation: Benchmarking with kappa carrageenan. Journal of Applied Polymer Science 133(2): 42263.
59. Thakur R, Saberi B, Pristijono P, Golding J, Stathopoulos C, et al. (2016) Characterization of Rice Starch- I-Carrageenan Biodegradable Edible Film. Effect of Stearic Acid on the Film Properties. International Journal of Biological Macromolecules 93(Pt A): 952-960.

60. Slavutsky AM, Bertuzzi MA (2016) Improvement of water barrier properties of starch films by lipid nanolamination. Food Packaging and Shelf Life 7: 41-46.

61. Matta Fakhouria FM, Martelli SM, Caon T, Velasco JI, Innocentini Mei LH (2015) Edible films and coatings based on starch/gelatin: Film properties and effect of coatings on quality of refrigerated Red Crimson grapes. Postharvest Biology and Technology 109: 57-64.

62. Sessini V, Arrieta MP, Kenny JM, Peponi L (2016) Processing of edible films based on nano-reinforced gelatinized starch. Polymer Degradation Stability 132: 157-168.

63. Badwaik LS, Borah PK, Deka SC (2014) Antimicrobial and enzymatic antibrowning film used as coating for bamboo shoot quality improvement. Carbohydrate Polymers 103: 213-220.

64. Chiumarelli M, Hubinger MD (2014) Evaluation of edible films and coatings formulated with cassava starch, glycerol, carnauba wax and stearic acid. Food Hydrocolloids 39: 20-27.

65. Ortega TR, Jiménez MA Talens OP, Chiralt A (2014) Effect of the incorporation of surfactants on the physical properties of corn starch films. Food Hydrocolloids 38: 66-75.

66. Kanmani P, Taik Lim S (2013) Development and characterization of novel probiotic-residing pullulan/starch edible films. Food Chemistry141(2): 1041-1049.

67. Bahareh S, Rahul T, Quan VV, Suwimol C, John BG, et al. (2016) Optimization of physical and optical properties of biodegradable edible films based on pea starch and guar gum. Industrial Crops and Products 86: 342-352.

68. Costa GI, dos Reis KC, Tavares MEG, Costa RA, Ferreira da Silva T, et al. (2016) Cellulose micro fibrillated suspension of carrots obtained by mechanical defibrillation and their application in edible starch films. Industrial Crops and Products 89(30): 285-294.

69. Mei J, Yuan y, Wu Y, Li Y (2013) Characterization of edible starchchitosan film and its application in the storage of Mongolian cheese. International Journal of Biological Macromolecules 57: 17-21.

70. Hucheng L, Yanfang R, Kun X, Simeng W, Yongzheng Z, et al. (2012) Effects of Chinese herbal medicine-starch-chitosan composite coating on fresh-keeping of ponkan. Transactions of the Chinese Society of Agricultural Engineering 28 (SUPPL.1): 300-305.

71. Avola C, Licciardello F, Mazzaglia A, Giannone V, Zanti C, Muratore G (2011) Quality evaluation of shrimps (Parapenaeuslongirostris) as affected by edible films. Italian Journal of Food Science 23(Suppl): 99102.

72. Ghanbarzadeh B, Almasi H, Entezami AA (2010) Physical properties of edible modified starch/carboxymethyl cellulose films. Innovative Food Science \& Emerging Technologies 11(4): 697-702.

73. Vásconez MB, Flores SK, Campos CA, Alvarado J, Gerschenson LN (2009) Antimicrobial activity and physical properties of chitosantapioca starch based edible films and coatings. Food Research International 42: 762-769.

74. Santacruz S, Rivadeneira C, Castro M (2015) Edible films based on starch and chitosan. Effect of starch source and concentration, plasticizer, surfactant's hydrophobic tail and mechanical treatment. Food Hydrocolloids 49: 89-94.

75. Kester JJ, Fennema OR (1986) Edible films and coatings: a review. Food Technology 40: 47-59. 
76. Kaur B, Ariffin F, Bhat R, Karim AA (2012) Progress in starch modification in the last decade. Food Hydrocolloids 26(2): 398-404.

77. Jansson C, Puthigae S, Sun C, Grenthe C (1995) Genetically modified starch as an industrial raw material. Journal of Macromolecular Science, Part A: Pure and Applied Chemistry 32(4): 895-898.

78. Shah U, Naqash F, Gani A, Masoodi FA (2016) Art and Science behind Modified Starch Edible Films and Coatings: A Review. Comprehensive Reviews in Food Science and Food Safety 15(3): 568-580.

79. Lago VES, do Nascimento P, Fontes EAF, Mauro MA, Kimura M (2013) Edible coatings from native and modified starches retain carotenoids in pumpkin during drying. LWT - Food Science and Technology 50(2): 420-425.

80. Ochoa TA, Almendárez BEG, Reyes AA, Pastrana DMR, López GFG, et al. (2017) Design and Characterization of Corn Starch Edible Films Including Beeswax and Natural Antimicrobials. Food and Bioprocess Technology 10(1): 103-114.

81. Gomes MA, Ascheri DPR, De Campos AJ (2016) Characterization of edible films of Swartziaburchelliphosphated starches and development of coatings for post-harvest application to cherry tomatoes. Semina: Ciencias Agrarias 37(4): 1897-191.

82. Pérez E, Segovia X, Tapia MS, Schroeder M (2012) Native and crosslinked modified Dioscorea trifida (cush-cush yam) starches as biomatrices for edible films. Journal of Cellular Plastics 48(6): 545-556.

83. Gutiérrez TJ, Morales NJ, Pérez E, Tapia MS, Fama L (2015a) Physico-chemical properties of edible films derived from native and phosphatedcush-cush yam and cassava starches. Food Packaging Shelf Life 3: 1-8.

84. Gutiérrez TJ, Tapia MS, Pérez E, Fama L (2015b) Structural and mechanical properties of edible films made from native and modified cush-cush yam and cassava starch. Food Hydrocolloids 45: 211-217.

85. Gutiérrez TJ, Morales NJ, Tapia MS, Pérez E, Famá L (2015 c) Corn starch 80:20 "waxy":regular, "native" and phosphated, as bio-matrixes for edible films. Procedia Materials Science 8: 304-310.

86. Gutiérrez TJ, Pérez E, Guzmán R, Tapia MS, Famá L (2014) Physicochemical and functional properties of native and modified by crosslinking, dark-cush-cush yam (Dioscorea trifida) and Cassava (Manihot Esculenta) Starch. Journal of Polymer and Biopolymer Physics Chemistry 2(1): 1-5.

87. González SP, Medina JC, Famá L, Goyanes S (2016) Data of thermal degradation and dynamic mechanical properties of starch-glycerol based films with citric acid as crosslinking agent. Data Brief 7(1) 1331-1334
88. Paz PSP, Mosquera SSA, Villada CHS (2016) Evaluation of permeability of an edible coating made from natural and modified cassava starch. Vitae 23: S222-S225.

89. Guimarães IC, dos Reis KC, Menezes EG, Borges PR, Rodrigues AC, et al. (2016) Combined effect of starch/montmorillonite coating and passive MAP in antioxidant activity, total phenolics, organic acids and volatile of fresh-cut carrots. International Journal of Food Sciences and Nutrition 67(2): 141-152.

90. Gutiérrez T, González G (2016) Effects of exposure to pulsed light on surface and structural properties of edible films made from cassava and taro starch. Food and Bioprocess Technology 9(11): 1812-1824.

91. Hu G, Chen J, Gao J (2009) Preparation and characteristic of oxidized potato starch films. Carbohydrate Polymers 76(2): 291-298.

92. Zamudio FPB, García ALE, Ramos MA, Tirado GJM, Bello PLA, et al (2013) Soluciones formadoras de película a base de almidón oxidado de avena mezcladas con quitosano: caracterización reológica y propiedades mecánicas de sus películas. Revista Iberoamericana de Polímeros 14(6): 293-304.

93. Galus S, Mathieu H, Lenart A, Debeaufort F (2012) Effect of modified starch or maltodextrin incorporation on the barrier and mechanical properties, moisture sensitivity and appearance of soy protein isolatebased edible films. Innovative Food Science \& Emerging Technologies 16: 148-154.

94. Solís JDA, Pineda SLN, Mosquera SSA, Hoyos CJL, Villada CHS (2015) Coating Effect of Modified Cassava Starch in Hass Avocado. Producción + Limpia 10(2): 31-37.

95. Tumwesigye KS, Sousa AR, Oliveira JC, Sousa-Gallagher MJ (2017) Food Packaging and Shelf Life. 13: 1-14.

96. Qiu L, Hu F, Peng Y (2013) Structural and mechanical characteristics of film using modified corn starch by the same two chemical processes used in different sequences. Carbohydrate Polymers 91(2): 590-596.

97. Wogguma T, Sirivongpaisal P, Wittaya T (2014) Properties and characteristics of dual-modified rice starch based biodegradable films. International Journal of Biological Macromolecules 67: 490-502.

98. Pérez GA, Bello PLA, García AB, Montejano GG, Barbosa CG, et al. (2012) Effect of structural characteristics of modified waxy corn starches on rheological properties, film-forming solutions, and on water vapor permeability, solubility, and opacity of films. Starch - Stärke 64(1): 27 36.

99. Senna MM, El-Shahat HA, El-Naggar AWM (2011) Characterization of gamma irradiated plasticized starch/poly (vinyl alcohol) (PLST/PVA) blends and their application as protected edible materials. Journal of Polymer Research 18(4): 763-771.

\section{Your next submission with Juniper Publishers will reach you the below assets}

- Quality Editorial service

- Swift Peer Review

- Reprints availability

- E-prints Service

- Manuscript Podcast for convenient understanding

- Global attainment for your research

- Manuscript accessibility in different formats

(Pdf, E-pub, Full Text, Audio)

- Unceasing customer service

Track the below URL for one-step submission https://juniperpublishers.com/online-submission.php 